\section{DISEÑO DE ENZIMAS POR EVOLUCIÓN MOLECULAR DIRIGIDA.}

DOI: http://dx.doi.org/10.18567/sebbmdiv ANC.2021.12.1

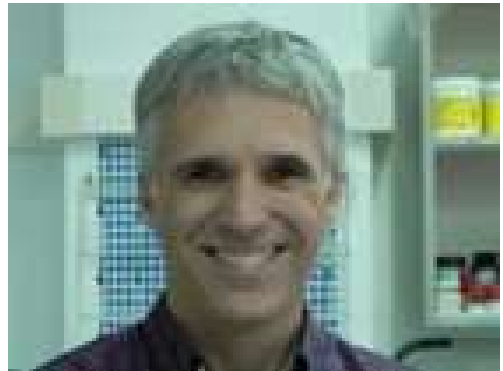

\author{
Miguel Alcalde \\ Instituto de Catálisis y Petroleoquímica. CSIC. Madrid
}

\section{Biografía}

Miguel Alcalde es Profesor de Investigación en el Instituto de Catálisis y Petroleoquímica del CSIC y fundador de EvoEnzyme, compañía spin-off derivada de su trabajo sobre enzimas diseñadas

por evolución dirigida para diversas aplicaciones biotecnológicas. El Dr. Alcalde es biólogo de formación, con postdoctorado en CALTECH en el grupo de la Prof. Frances Arnold (premio Nobel en Química 2018) y diversas estancias posteriores en CALTECH y

UMASS. Coautor de más de un centenar de trabajos sobre

diseño de enzimas y biocatálisis aplicada y 14 patentes de

invención, ha dirigido 35 proyectos de investigación procedentes de fondos públicos y privados y 12 Tesis Doctorales.

\title{
Resumen
}

La evolución molecular dirigida es una estrategia revolucionaria de ingeniería de proteínas, anticuerpos o incluso microorganismos completos con características mejoradas. Esta metodología ha permitido el diseño de enzimas con propiedades excepcionales posicionando la biocatálisis en un lugar de privilegio en el arcoíris de disciplinas biotecnológicas.

\section{Summary}

Directed molecular evolution is a revolutionary strategy to engineer proteins, antibodies or even whole microorganisms with improved traits. This approach has allowed superior enzymes to be designed while positioning biocatalysis in a place of privilege within the biotechnology rainbow.

Las enzimas son biocatalizadores exquisitamente selectivos que pueden acelerar las reacciones químicas en los seres vivos, llevando a cabo las transformaciones más complejas en condiciones muy respetuosas con el entorno natural, a temperatura ambiente, presión atmosférica y en solución acuosa. Por este motivo, se consideran catalizadores verdes y la biotecnología persigue su uso para sustituir los nocivos procesos químicos todavía reinantes en diversos escenarios energéticos e industriales. Sin embargo, trasladar el comportamiento de una enzima desde su ambiente natural a una aplicación de interés para la sociedad, desde la producción de un fármaco a la degradación de contaminantes, no es tarea fácil. Bajo circunstancias alejadas de su ámbito de trabajo natural, la mayoría de las enzimas se inactivan, no son estables o lo suficientemente eficientes por la sencilla razón de que han evolucionado y se han especializado para cumplir con tareas definidas en ambientes celulares muy determinados. Sin embargo, ahora es posible manipular - modificar genéticamente- enzimas al antojo del investigador, para adquirir nuevas propiedades, mejorar y/o adaptar las que ya poseen con el fin último de ser aplicadas en reacciones de interés en el marco de la sostenibilidad y economía circular. Para ello se hace uso de una revolucionaria herramienta conocida como evolución molecular dirigida, que explota el inmenso potencial de la evolución natural para el diseño de enzimas de nuevo cuño.

La evolución dirigida emula el proceso de evolución natural, pero a escala de laboratorio: mediante ciclos sucesivos de mutagénesis aleatoria, recombinación de ADN y selección se consiguen enzimas más potentes y versátiles, con nuevos atributos, al tiempo que se comprime la escala temporal de la evolución natural, desde miles de millones de años, hasta tan solo meses o semanas de trabajo en el laboratorio. Al contrario de lo que sucede en los procesos de evolución natural, la evolución dirigida no ocurre de manera espontánea durante la reproducción y supervivencia de los individuos, sino que se encuentra bajo el estricto control del investigador, que "dirige" el proceso selectivo en direcciones muy determinadas. Por evolución dirigida se pueden diseñar nuevas selectividades (quimio-, regio- y enantio-selectividades), mejorar estabilidades frente a temperatura, pHs extremos, resistencia a inhibidores o crear nuevas funciones no planteadas en la naturaleza ( $p . e j$. se han diseñado enzimas evolucionadas que llevan a cabo reacciones no naturales para la formación de enlaces C-Si o C-B a través de la apertura de su promiscuidad de función catalítica).

El impacto de la evolución dirigida en nuestra sociedad es cuantificable, con decenas de procesos regidos por enzimas evolucionadas en el laboratorio, y que se aplican desde la producción de medicamentos para el tratamiento del cáncer o diabetes, la reducción de la huella de carbono 
mediante procesos de captura y secuestro de $\mathrm{CO}_{2}$, hasta la producción de nuevas formas de energía renovables.

Por todas estas razones, la inventora de esta estrategia de ingeniería de proteínas, la Profesora Frances $\mathrm{H}$. Arnold de CALTECH, fue galardonada por el premio Nobel en Química en la edición del año 2018.

Actualmente, el desarrollo de potentes métodos computacionales predictivos basados en inteligencia artificial (Machine-Deep Learning), permite realizar una evolución dirigida más rápida y eficiente, al tiempo que se suman avances en edición de genomas mediante CRISPR-Cas9 para abordar la evolución dirigida, no solo de enzimas y anticuerpos sino también de complejas rutas metabólicas o incluso microorganismos completos. Junto a estas líneas, el auge de algoritmos de predicción de estructuras 3D de proteínas (AlphaFold2) conducirá en los años venideros hacia una evolución dirigida estructuralmente guiada como nunca antes hubiéramos imaginado. No menos importante, el enorme incremento de secuencias proteicas depositadas en bases de datos a partir de estudios genómicos y metagenómicos, junto con el precio cada vez más asequible para la síntesis de genes, conducen a un extenso portfolio de puntos de partida prometedores, a partir de los cuales se pueden evolucionar enzimas modernas a medida, o incluso permitir la evolución de enzimas ancestrales: Enzimas pertenecientes a organismos ya extintos, cuyas secuencias han sido inferidas filogenéticamente mediante herramientas computacionales y expresadas en microorganismos modernos, i.e. "resucitadas" en el laboratorio.

En nuestro laboratorio del Instituto de Catálisis y Petroleoquímica del CSIC (https://miguelalcaldelab.eu) y en nuestro spin-off (https://evoenzyme.com) estamos realizando esfuerzos sinérgicos para el diseño de enzimas evolucionadas de última generación, quiméricas, modernas y ancestrales, con propiedades híbridas para diferentes fines: desde la degradación y valorización de residuos plásticos de diferente naturaleza con enzimas promiscuas altamente estables hasta la síntesis de metabolitos de fármacos humanos con enzimas versátiles y selectivas que funcionan a modo de "hígado artificial" para el diseño de nuevos medicamentos.

\section{Referencias:}

Molina-Espeja, P., Viña-Gonzalez, J., Gomez, B.J., Martin-Diaz, J., Garcia-Ruiz, E., and Alcalde, M. (2016). Beyond the outer limits of nature by directed evolution. Biotechnology Advances 34: 754-767.

Bornscheuer, U.T., Hauer, B., Erich, K., Jaeger, Schwaneberg, U. (2019). Directed Evolution Empowered Redesign of Natural Proteins for the Sustainable Production of Chemicals and Pharmaceuticals. Angewandte Chemie-International Edition 58: 36-40.

Arnold, F.H. (2019). Innovation by Evolution: Bringing New Chemistry to Life (Nobel Lecture). Angewandte Chemie-International Edition 58: 14420-14426.

Wang, Y., Cao, M., Yu, T., Lane, S.T. and Zhao, H. (2021). Directed Evolution: Methodologies and Applications. Chemical Reviews. In press. DOI: 10.1021/acs.chemrev.1c00260.

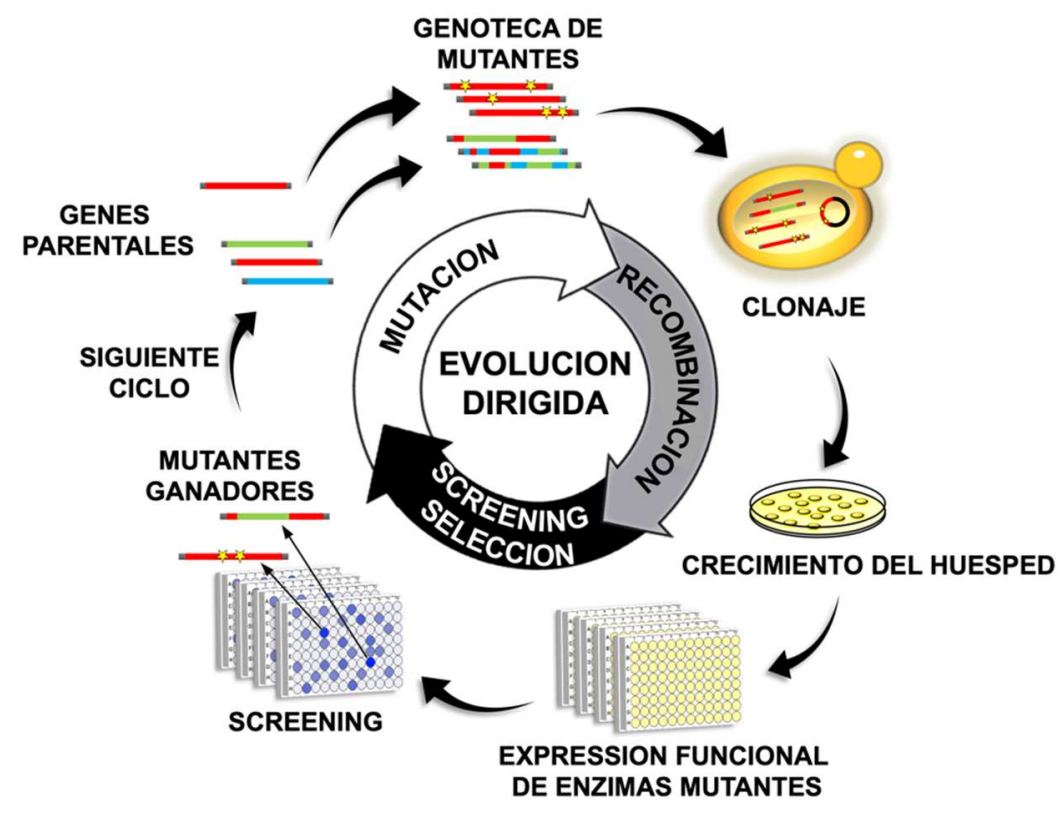

Figura 1. Representación esquemática de un proceso de evolución dirigida. 